\title{
De la ciudadanía suramericana al humanitarismo: el giro en la política y diplomacia migratoria ecuatoriana
}

\author{
From South American citizenship to humanitarianism: \\ the turn in Ecuadorian immigration policy and \\ diplomacy
}

Jacques Ramírez * (D) https://orcid.org/0000-0001-6334-2874

\begin{abstract}
${ }^{a}$ Universidad de Cuenca, Facultad de Filosofía, Programa de Antropología de lo Contemporáneo, Cuenca, Ecuador, correo electrónico: papodelalife1@gmail.com
\end{abstract}

\section{Resumen}

El objetivo del artículo es examinar los cambios en la política y diplomacia migratoria en Ecuador al poner atención a las medidas implementadas a partir del incre-

Recibido el 16 de marzo de 2020.

Aceptado el 5 de noviembre de 2020.

Publicado el 11 de noviembre de 2020.

*Autor para correspondencia: Jacques Ramírez. Correo electrónico: papodelalife1@gmail.com

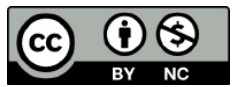

Esta obra está protegida bajo una Licencia Creative Commons Atribución-NoComercial 4.0 Internacional. mento de arribos de migrantes venezolanos. Con la llegada al poder del presidente Lenín Moreno, en dicho país andino se pasó de un enfoque de derechos a uno de seguridad amparado en la figura del gobierno humanitario, donde se ve a los migrantes tanto como víctimas y como amenazas. Metodológicamente se realiza un análisis de los principales decretos emitidos desde 2018 y se apoya en fuentes cuantitativas sobre flujos y visas otorgadas hasta agosto de 2020. El texto deja ver cómo el gobierno utiliza la diplomacia migratoria como un elemento central de su política exterior tanto para acercarse a la agenda de Washington, alejarse del eje bolivariano - principalmente del gobierno de Venezuela- y conseguir fondos de la cooperación internacional para hacer frente a la llegada de migrantes.

Palabras clave: Ecuador, diplomacia migratoria, humanitarismo, control, migración venezolana.

\section{Abstract}

The main purpose of the article is to examine the changes in migration policy and diplomacy in Ecuador paying attention to the measures taken since the increase on the arrivals of Venezuelan migrants. With the government of President Lenín Moreno, the focus shifted from rights to security under the figure of the humanitarian government, where migrants are seen as both victims and threats. Methodologically, an analysis is made of the main decrees issued since 2018 and is supported by quantitative sources on flows and visas granted until August 2020. The text shows how the government uses migratory diplomacy

CÓMO CITAR: Ramírez, J. (2020). De la ciudadanía suramericana al humanitarismo: el giro en la política y diplomacia migratoria ecuatoriana [From South American citizenship to humanitarianism: the turn in Ecuadorian immigration policy and diplomacy]. Estudios Fronterizos, 21, e061. https://doi.org/10.21670/ref.2019061 
as a central element of its foreign policy both to get closer to Washington's agenda, to move away from the Bolivarian axis - mainly from the Venezuelan governmentand to obtain funds from international cooperation to face the increase of migrants.

Keywords: Ecuador, migration diplomacy, humanitarianism, control, Venezuelan migratrion.

\section{Introducción: la diplomacia migratoria del gobierno humanitario}

"He dispuesto la conformación inmediata de brigadas para controlar la situación legal de los inmigrantes venezolanos en las calles, en los lugares de trabajo y en la frontera", señalaba el presidente Lenín Moreno a inicios de 2019, meses después impuso una visa de entrada a los venezolanos al tenor de lo que han realizado otros países de Suramérica como Perú y Chile. Con estas medidas, implementadas vía decreto, se terminó de concretar el giro que dio el gobierno de Ecuador en relación con la política migratoria regional al pasar de un enfoque de derechos, libre movilidad y facilidades de residencia hacia uno más restrictivo, de control y seguridad fronteriza, denominado asistencia humanitaria.

El objetivo central de este artículo es examinar cuáles son los principales cambios en la política y diplomacia migratoria ecuatoriana desde la llegada al poder del actual gobierno. Como han resaltado algunos autores (Herrera Ríos, 2016; Ramírez, 2013) en la llamada década correísta (2007-2017) se produjo un nuevo tratamiento de los temas migratorios. Producto de esto, Ecuador se constituyó en un referente a nivel regional y global al intentar construir una política de movilidad humana con enfoque de derechos. ${ }^{1}$

La incorporación de este enfoque vino acompañada de políticas que no solo dieron un aire nuevo a la forma histórica de entender la migración en el país (que llevó incluso a los límites de la imaginación política), sino que colocaron a los asuntos migratorios como un componente central en la gestión gubernamental lo cual dio paso al surgimiento de una activa diplomacia migratoria que puso al Ecuador en el radar de la geopolítica mundial.

Por diplomacia migratoria entendemos, al seguir a Adamson y Tsourapas (2019), cómo los estados emplean la gestión de la migración en sus relaciones internacionales, es decir, en cómo esta se vincula con los objetivos diplomáticos del Estado. Como bien advierten los autores citados, la diplomacia migratoria no es sinónimo de la política general de migración, esta se vuelve relevante cuando los estados la incluyen como parte de sus relaciones exteriores y diplomáticas y se convierte en un elemento importante y de impacto en las relaciones interestatales.

Si bien existen muy pocos trabajos que analizan el vínculo entre diplomacia y movilidad, Tsourapas ha introducido el término de diplomacia de la migración (migration diplomacy) para entender la utilización de instrumentos, procesos y procedimientos diplomáticos para gestionar la movilidad transfronteriza de la población, lo que incluye tanto la utilización estratégica de las corrientes migratorias

\footnotetext{
${ }^{1}$ Al respecto véase: Plan de Desarrollo Humano de las Migraciones (2007-2013), Constitución de la República (2008), Agenda de Igualdad de Movilidad Humana (2013-2017), Ley Orgánica de Movilidad Humana (2017).
} 
como medio para obtener otros objetivos, como el uso de métodos diplomáticos para lograr objetivos relacionados con la migración (Tsourapas, 2017, p. 2370).

En efecto, desde 2007, Ecuador incluyó en su agenda de política exterior, tanto bilateral como multilateral, los asuntos migratorios que no solo colocaron en la mesa de debate y negociación el enfoque de derechos sino también propuestas concretas para una nueva forma de manejar la "cuestión migratoria" sobre todo a nivel intrarregional. Entre las acciones más reconocidas sobresalen: proponer el principio de ciudadanía universal, eliminar las visas de ingreso al país para todos las nacionalidades, reconocer como refugiados a casi 30000 colombianos entre 2009 y 2010 (en una coyuntura de ruptura diplomática con Colombia), dar residencia a migrantes haitianos afectados por el terremoto de 2010, impulsar la propuesta de ciudadanía suramericana en el seno de la Unión de Naciones Suramericanas (Unasur) e incorporar esta noción en su marco legal. Sin embargo, el conceder el asilo diplomático en la embajada de Ecuador en Londres al fundador de WikiLeaks, Julian Assange, en junio de 2012, constituyó el caso emblemático de la diplomacia migratoria implementada en el gobierno de Rafael Correa. ${ }^{2}$

Cuando llega al poder el gobierno de Moreno (mayo de 2017) gradualmente va girando su diplomacia y el enfoque de la política exterior va alejándose del eje bolivariano, alineándose con los países del Grupo de Lima $^{3}$ y con la agenda de Washington. Esto trajo implicaciones en la relación con el gobierno de Venezuela y en el tratamiento de la diplomacia migratoria, sobre todo en lo referente al flujo migratorio de cientos de miles de migrantes venezolanos que empezaron a llegar en los últimos años.

El gobierno nacional empieza a denominar a la migración venezolana como "éxodo migratorio" o "crisis migratoria" con un triple objetivo en su política exterior: en primer lugar, para ejemplificar el fracaso del llamado "socialismo del siglo xxi y la dictadura de Maduro"; en segundo lugar, para conseguir fondos internacionales y así hacer frente a la llegada de los migrantes venezolanos; y, en tercer lugar, para revestir el discurso y las acciones con el adjetivo de humanitario. Se habló de "emergencia humanitaria", "asistencia humanitaria", "corredor humanitario" y finalmente se impuso una "visa humanitaria".

Es decir, se presenta como un gobierno humanitario, entendido como el despliegue de sentimientos morales en las políticas —en este caso migratorias, que incluyen discursos y prácticas de intervención gubernamental- en las cuales el sufrimiento aparece como un nuevo léxico que justifica las prácticas de asistencia (Fassin, 2016, 2018 ) y que colocan en un primer momento a los migrantes venezolanos como víctimas que sufren las consecuencias del mal gobierno de Maduro.

Este tratamiento trae consigo acciones que Pereira (2019) denomina humanismo de prevención donde se considera la migración como un riesgo y a los migrantes como víctimas. Esto implica una forma de nexo entre migración y seguridad, que tiene por

\footnotetext{
2 Para un análisis detallado de la política migratoria en este periodo véase: Ramírez $(2013,2017)$ y Herrera Ríos (2016).

${ }^{3}$ El grupo de Lima está conformado por: Argentina, Brasil, Canadá, Chile, Colombia, Costa Rica, Guatemala, Honduras, México, Panamá, Paraguay, Perú, Guyana, Santa Lucía y recientemente por el gobierno interno de Bolivia. Este espacio es apoyado desde afuera por Estados Unidos y se debe aclarar que, desde la llegada de Andrés Manuel López Obrador a la presidencia de México, este país no ha asistido a los últimos encuentros. Ecuador es país observador.
} 
resultado realizar un conjunto de medidas preventivas y de control migratorio más sutiles. Sin embargo, un evento de violencia, que terminó en feminicidio, ocurrido en el último año en el cual estuvo involucrado un migrante venezolano, más la estigmatización hacia esta población (Ramírez, et al., 2019) propician que el gobierno gire hacia una postura de humanismo de expiación, donde los migrantes empiezan a ser vistos como una metaamenaza al orden social (económico, añadiría) y político nacional lo que conduce a una securitización y control represivo de la migración (Pereira, 2019, p. 304). ${ }^{4}$ En relación con el tema social son vistos como los causantes del incremento de la delincuencia, a nivel económico como los responsables del incremento del desempleo y en lo político como actores que impulsan las manifestaciones y desestabilizaciones al gobierno, como se verá más adelante. De esta manera, según la coyuntura y la estrategia gubernamental, los migrantes son percibidos como víctimas o amenazas. La primera caracterización es utilizada más en el ámbito de la diplomacia migratoria y la segunda cuando se dirige al público nacional.

En el giro que da el gobierno, la llegada de migrantes venezolanos es utilizada como un objetivo de su política exterior que terminó no solo por romper las relaciones diplomáticas con el gobierno de Nicolás Maduro, sino que le permitió crear y liderar un nuevo espacio como fue el Proceso de Quito, ${ }^{5}$ el cual tiene como objetivo dar una respuesta regional a la crisis migratoria venezolana, sin embargo desde este espacio también se han pronunciado sobre el problema estructural que se vive en dicho país y han declarado estar comprometidos con una solución política, pacífica y democrática, conducida por los propios venezolanos (Villareal, 2019), en un claro ejemplo de diplomacia migratoria coercitiva (Tsourapas, 2017). ${ }^{6}$

Si bien las leyes de migración, los acuerdos, decretos, reglamentos y las propias políticas en esta materia constituyen instrumentos valiosos de la diplomacia migratoria, en este artículo queremos complementar este enfoque al señalar que la diplomacia migratoria no solo es utilizada como instrumento de la política internacional, sino también para la política nacional. Veremos más adelante cómo las primeras decisiones implementadas por el gobierno para contener el flujo (agosto de 2018) no lograron concretarse. Es a partir de la creación del Proceso de Quito (septiembre de 2018) y de las declaraciones y planes de acción que de allí emanan, que estas son utilizadas como justificativos para las nuevas medidas "humanitarias" que se empiezan a implementar para contener el flujo migratorio. Esto con la particularidad, como nos recordaba Ticktin (2015), que estas políticas humanitarias incluyen elementos de seguridad y control de las migraciones.

Vale señalar que, si bien este texto se centra en las políticas implementadas para responder a la migración venezolana, a lo largo del tiempo otros migrantes también han sido vistos como un problema para el Estado, como fueron en su época los

\footnotetext{
${ }^{4}$ Vale resaltar que existe una reciente literatura que viene problematizando las miradas humanitaristas de la migración en la línea de Fassin (Ticktin, 2011, 2015) y en la región suramericana, complejizando la relación derechos humanos-seguridad-migración. Al respecto ver: Clavijo y cols. (2019) y Domenech (2017).

${ }^{5}$ Once países suscribieron la primera Declaración del Proceso de Quito: Argentina, Brasil, Chile, Colombia, Costa Rica, Ecuador, México, Paraguay, Perú y Uruguay.

6 "Defino la diplomacia migratoria coercitiva como la amenaza o el acto de un Estado, o de una coalición de Estados, de afectar tanto las corrientes migratorias hacia o desde un Estado objetivo o su población migratoria como castigo, a menos que el Estado objetivo acepte una demanda política o económica articulada. Esto recuerda el uso de sanciones positivas en las relaciones internacionales" (Tsourapas, 2017, p. 2370-2371).
} 
migrantes chinos, cubanos o haitianos. Sobre estos últimos, por ejemplo, no hay miras a una política de regularización permanente (Ceja \& Ramírez, en prensa). Incluso, ha sido tal la magnitud mediática y política en el tratamiento de la migración venezolana que se han invisibilizado al resto de inmigrantes (Pugh et al., 2020).

Varios gobiernos de Suramérica (como Macri en Argentina, Bolsonaro en Brasil, Piñera en Chile, Moreno en Ecuador, Duque en Colombia) se han mostrado más receptivos con la migración venezolana que con otros flujos al mostrar su rostro más "humanitario" (al crear permisos especiales y nuevas visas o al otorgar refugio) pero el trasfondo muestra parte de su estrategia de política exterior y diplomacia migratoria que ha girado en torno a la relación con el gobierno de Maduro, para criticar el modelo e incluso impulsar alguna intervención armada.

Para entender este cambio, y en específico el tratamiento de la migración venezolana, es necesario en primer lugar analizar los principales avances que en esta materia se realizaron en Ecuador durante los últimos años para luego centrarse en las nuevas políticas y acciones implementadas. Vale resaltar que el caso ecuatoriano no es aislado pues diferentes países de América del Sur han comenzado a experimentar cambios en sus políticas migratorias, ya sea con la llegada de gobiernos conocidos como de la "nueva derecha", como en Argentina (Penchaszadeh \& García, 2018), Brasil (Uebel \& Ranincheski, 2017), o aquellos donde han continuado en el poder gobiernos conservadores, como el caso de Colombia o Perú (Gissi, et al., 2020).

Este trabajo es un artículo analítico etnográfico que metodológicamente se basa en el estudio del corpus $^{7}$ de los principales decretos, resoluciones, informes, leyes y discursos oficiales en materia migratoria. Este material constituye la fuente central para ver los cambios y/o continuidades de la política a lo largo del tiempo, así como las respuestas gubernamentales a ciertos "eventos" (incremento de llegadas o problemas sociopolíticos) ocurridos en torno a la migración.

El estudio se complementa con información cuantitativa sobre flujos migratorios y visas otorgadas a venezolanas desde 2010 hasta agosto de 2020 (fecha en que terminó la entrega de las visas humanitarias ${ }^{8}$ ) y también de algunos datos estadísticos de una encuesta realizada en febrero de 2020 a migrantes mayores de 18 años, tanto hombres como mujeres. ${ }^{9}$ Esta información estadística nos permite tener una radiografía del perfil migratorio, de las condiciones de vida en la que se encuentran los migrantes en el país, así como complementar y/o contrarrestar con la información oficial.

\footnotetext{
${ }^{7}$ Corpus: conjunto de frases y textos del que pueden extraerse enunciados (Deleuze, 1991, p. 26).

${ }^{8}$ Todos los datos de flujos y visas son oficiales provenientes del Ministerio de Gobierno entregados vía oficio (Oficio número MDG-VDI-SDM-DSM-2019-6951-O) y del Ministerio de Relaciones Exteriores y Movilidad Humana (MREMHU, 2020) (Números de oficio: MREMH-SSMC-2020-0004-O; MREMH-VMH-2020-0319-O).

${ }^{9}$ Se elaboró un formulario de 74 preguntas, divididas en 11 secciones, las cuales se definieron con el fin de establecer una "línea de tiempo" entre diferentes momentos y espacios de la vida de las personas migrantes encuestadas. La encuesta fue realizada en la Provincia de Pichincha a migrantes radicados en dicho lugar, de los cuales el número de casos muestrales de migrantes venezolanos fue de 1431 . La encuesta tiene un margen de error de $\pm 2.4 \%$.
} 


\section{El marco jurídico vigente y la llegada de venezolanos}

La Constitución de la República del Ecuador, aprobada en 2008, constituyó un hito en este país dado que por primera vez se incluía una serie de principios en materia de movilidad humana que planteaban un diferente tratamiento de los temas migratorios, caracterizados por tener un enfoque de aperturismo segmentado al inicio el siglo xx y un enfoque de seguridad y control desde medianos del siglo pasado hasta inicios del Xxi (Ramírez, 2014).

Dicha carta magna no solo incorpora un nuevo enfoque para tratar el tema a nivel nacional, sino que plasmó una nueva óptica para entender el tema a escala planetaria. Aparte de reconocer que no existe ningún ser humano ilegal por su condición migratoria y el derecho a migrar (art. 40), planteó el principio de ciudadanía universal, la libre movilidad de todos los habitantes del planeta y el progresivo fin de la condición de extranjero como elemento transformador de las relaciones desiguales entre los países, especialmente en las relaciones Norte-Sur (art. 416/6). Estos artículos constituyeron la piedra angular del anterior gobierno en su diplomacia migratoria en el contexto de plantear el nuevo paradigma de convivencia denominado Buen Vivir (Ramírez, 2019).

Una de las primeras medidas que tomó el gobierno del ex presidente Rafael Correa fue eliminar las visas de ingreso para todas las nacionalidades en 2008, en "aplicación al principio de libre circularidad de personas y con el fin de fortalecer las relaciones entre Ecuador y todos los países del mundo y promover el turismo" (MREMHU, 2008). ${ }^{10}$ Esta decisión causó preocupación y malestar en varios gobiernos dado que Ecuador se convirtió en la puerta de entrada para muchos migrantes en tránsito provenientes de varias latitudes que iban tanto al norte (Estados Unidos de América [EUA]) como al sur (Brasil o Argentina), ${ }^{11}$ lo que se convirtió en tema de discusión y tensión en varios foros intergubernamentales.

A nivel internacional se buscó la firma de convenios bilaterales y multilaterales, uno de ellos se concretó en 2010 con la República Bolivariana de Venezuela, el denominado Estatuto Migratorio. En el preámbulo de dicho acuerdo se observan una serie de principios con un enfoque de derechos: "no existen seres humanos ilegales, no a la criminalización y penalización de la migración irregular, respeto irrestricto a los derechos humanos de las personas migrantes y a la libre movilidad". Este convenio constituye uno de los primeros postconstituyentes en aterrizar en política promigrantes.

Bajo este enfoque, en el Estatuto Migratorio se estipulan varios artículos que tienen como objetivo dar facilidades para que los ciudadanos de ambos países que quieran residir en el otro de manera temporal o permanente puedan hacerlo. Hay que resaltar que al momento de suscribir el acuerdo había más presencia de ecuatorianos

\footnotetext{
${ }^{10}$ Dos años después de implementada tal política se impuso visa para ingresar al Ecuador a ciudadanos provenientes de 12 países de África, Asia y el Caribe, aduciendo un inusual flujo migratorio. A partir de 2019 el actual gobierno exigió visa a 18 países más, siendo en total 30 nacionalidades las que actualmente tienen que presentar visa de ingreso.

${ }^{11} \mathrm{Al}$ respecto ver Moreno (2019) y Ménard (2017).
} 
en Venezuela que venezolanos en Ecuador. ${ }^{12}$ Sin embargo, dicho estatuto migratorio benefició a los primeros venezolanos que decidieron radicarse en Ecuador.

Si bien los venezolanos hasta el año 2015 no estaban dentro de los principales grupos de inmigrantes, su crecimiento aparece en 2016, se dispara en 2017 y continúa creciendo exponencialmente hasta alcanzar la cifra de casi un millón de personas que entraron en 2018 (Figura 1). A diferencia de lo que ocurría anteriormente, se observa que, desde 2016, las entradas y las salidas ya no van de la mano, lo cual advierte el incremento de personas que llegan del país llanero y se quedan en Ecuador.

Figura 1: Entradas y salidas de venezolanos a Ecuador 2010-2019

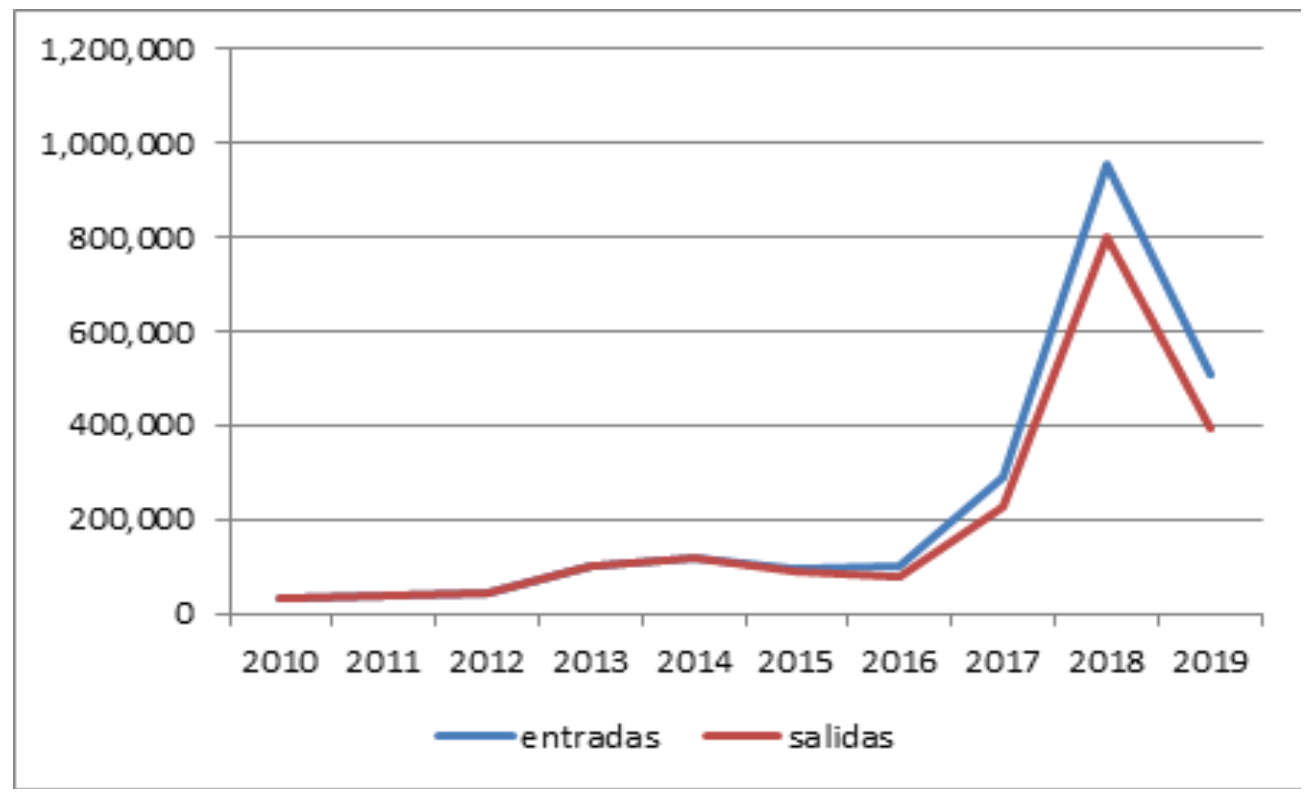

Fuente: Elaboración propia con base en información del Ministerio de Gobierno, Ecuador.

Para 2019 disminuyeron los flujos y el saldo migratorio (Figura 2) como efecto de las políticas restrictivas implementadas por el gobierno de Moreno. Hay que resaltar que Ecuador es principalmente un país de tránsito de esta migración pues, de toda la población venezolana que entró al Ecuador en la última década, solo 16\% decidió quedarse. Si se toma como referencia de análisis el periodo 2016-2019, tiempo en que se produce la estampida migratoria de venezolanos, llegaron al país aproximadamente 1850000 y el porcentaje de los que se quedaron llega a $19 \%$.

\footnotetext{
${ }_{12}$ Como es de conocimiento público, en la década de 1970 se produce una bonanza petrolera en Venezuela que generó un aumento del PIB, motivo por el cual se la conoció como "la Venezuela saudita" que atrajo a muchos inmigrantes, entre ellos a ecuatorianos (Banda \& Lesser, 1987). Vale recordar que anteriormente Venezuela había firmado ya algunos convenios con otros países del eje bolivariano, entre ellos con Cuba, para intercambiar "petróleo venezolano por médicos cubanos" como otro ejemplo del uso de la diplomacia migratoria.
} 
Figura 2: Saldo migratorio de venezolanos en Ecuador 2010-2019

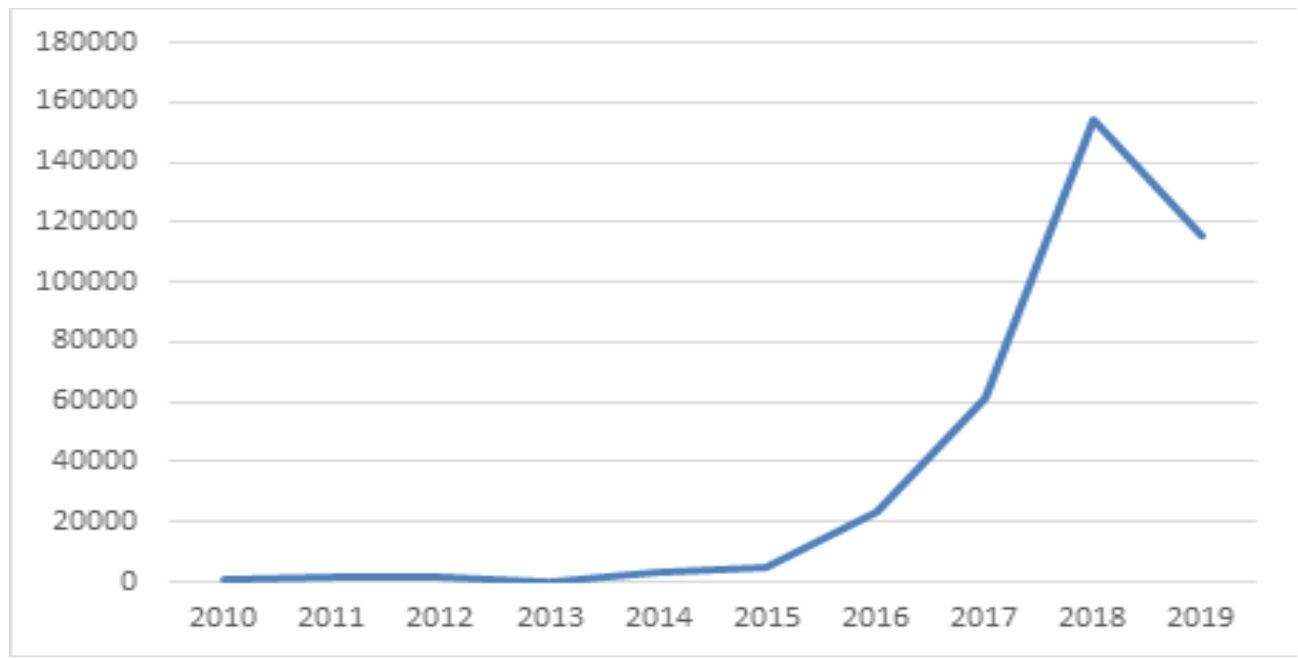

Fuente: Elaboración propia con base en información del Ministerio de Gobierno, Ecuador.

Las primeras personas que se asentaron en Ecuador lograron hacerlo justamente a través del Estatuto Migratorio, conocido como la "visa convenio". En efecto, entre enero de 2013 y diciembre de 2016, el Estado ecuatoriano otorgó 27224 visas a ciudadanos venezolanos, de ellas más de 13000 se dieron gracias al Estatuto. De ahí, siguen las visas profesionales (5 500), de amparo (3 000) y de trabajo (2 200), aproximadamente (Figura 3). Se destaca que al ser las visas profesionales las segundas más solicitadas, esto nos da una idea del perfil migratorio de los primeros venezolanos, muchos de ellos con altos niveles de escolaridad, lo que se conoce como migrantes calificados. Efectivamente, de la encuesta realizada se desprende que de los primeros migrantes venezolanos que entraron al país, 37.5\% tenía estudios universitarios completos. Veremos más adelante cómo este porcentaje baja entre los migrantes recientes.

Figura 3: Visas entregadas a ciudadanos venezolanos (2013-2016)

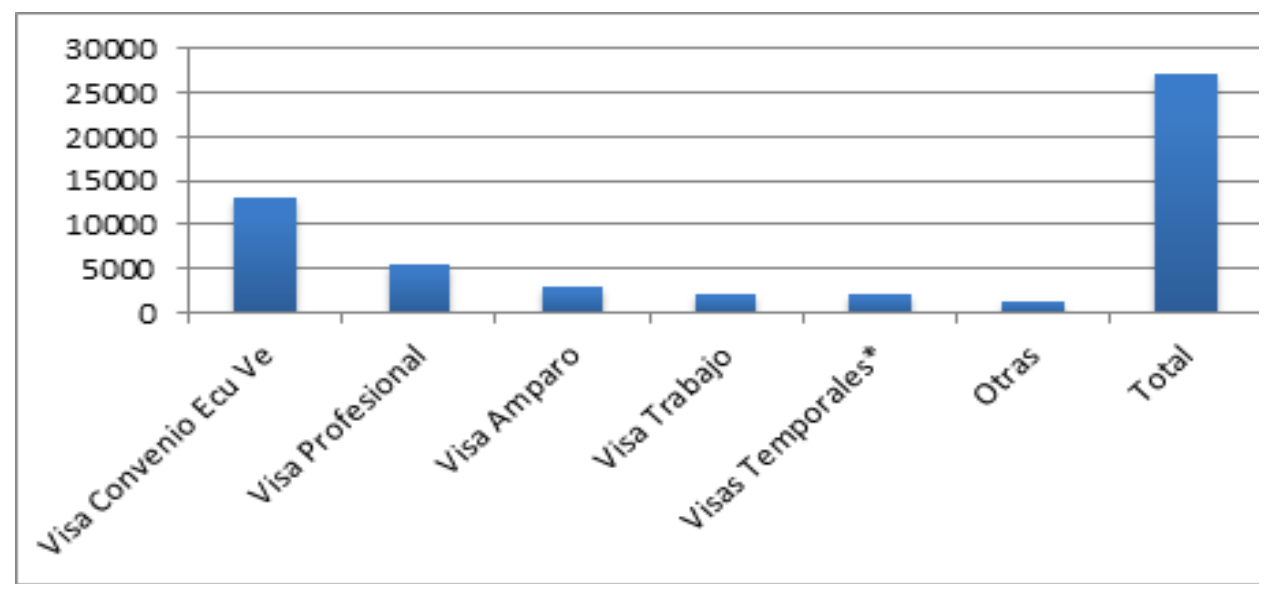

Fuente: Elaboración propia con base en información del Ministerio de Relaciones Exteriores y Movilidad Humana, Ecuador.

*Visas temporales con fines de: turismo, deporte, salud, estudio, ciencia, arte y actos de comercio. 
Con la aprobación y puesta en marcha de la nueva Ley de Movilidad Humana, a inicios de 2017, se incorporaron nuevas categorías, entre ellas la categoría de ciudadanía suramericana. Bajo este concepto y propuesta teórico-política, que fue impulsada desde Unasur, se dieron facilidades para que puedan obtener la residencia las personas de la región. El concepto de ciudadanía suramericana es incorporado por Ecuador y constituye el único país de la región que lo incluye en su marco normativo. Por dicha noción se entiende:

la condición jurídica de acceso progresivo a derechos, deberes y obligaciones por parte de los ciudadanos y ciudadanas de la Unasur. Es una ampliación, no sustitutiva, de las ciudadanías nacionales. Asimismo, es la condición de identidad, pertenencia y arraigo a la tierra suramericana, a sus tradiciones y costumbres, a sus culturas diversas, a sus lenguas e idiomas y a sus cosmovisiones, cuyo fundamento primario es la historia compartida de los países miembros de la Unasur (Ramírez, 2016, p. 14).

Aunque se basa en una propuesta pro derechos (implícita incluso en el propio concepto de ciudadanía) que brinda facilidades para la regularización con la sola presencia de una solicitud de residencia, pasaporte o cédula y el pago de la tarifa, no se dejaron de lado ciertas miradas de control y seguridad.

Pese a ello, al no solicitar ningún requisito vinculado a la actividad laboral ni a la solvencia económica del solicitante, la conocida como "visa Unasur" ha constituido el principal mecanismo de regularización para los ciudadanos suramericanos. Con este instrumento se han regularizado 91762 personas en tres años (2017-2019), 92\% migrantes venezolanos, $6 \%$ colombianos y 2\% del resto de países de la región (Figura 4).

Figura 4: Visas Unasur según nacionalidad, 2017-2019

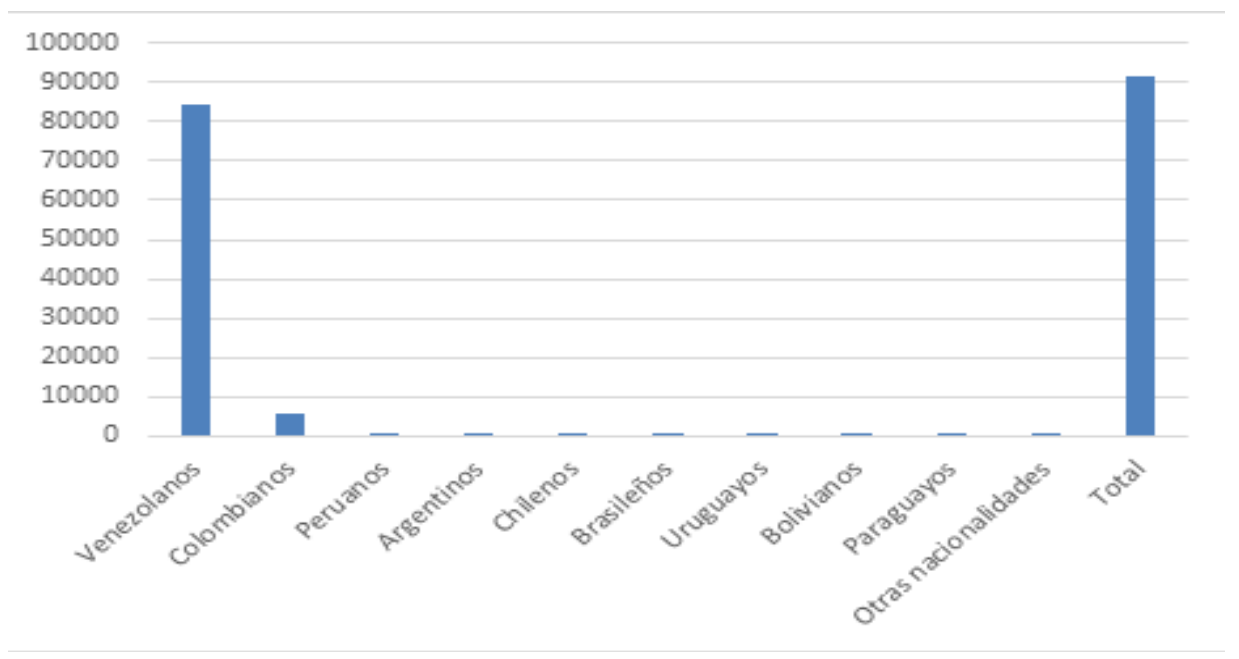

Fuente: Elaboración propia con base en información del Ministerio de Relaciones Exteriores y Movilidad Humana, Ecuador. 
Miles de venezolanos optaron por esta vía para obtener su residencia. Desde febrero de 2017, cuando el gobierno ecuatoriano empezó a otorgarla, hasta diciembre de 2019 se entregaron 84350 visas Unasur. Se observa claramente que la estrategia de residencia de los venezolanos en Ecuador cambió al dejar de solicitar la "visa convenio" (utilizada hasta 2016) y optar por la "visa Unasur". Vale resaltar también la disminución de la visa profesional, lo cual confirma el cambio de perfil de los últimos venezolanos en arribar al país y la dificultad por obtener ciertos documentos apostillados como el título profesional.

Los datos de los venezolanos que han optado por quedarse en Ecuador y obtener un permiso de residencia dejan ver que muy pocos caen en la categoría de refugiados o necesitados de protección internacional. Apenas $3 \%$ de los venezolanos, en los dos últimos años, optó por el refugio. ${ }^{13}$ Como se verá más adelante, el gobierno introdujo a finales de 2019 una nueva visa "por razones humanitarias" que también empieza a ser utilizada.

El número total de visas entre temporales y permanentes otorgadas a migrantes venezolanos entre 2017 y 2019 es de 112 315, de las cuales $75 \%$ fueron las visas Unasur. Si bien dicha visa ha dado facilidades para la regularización de migrantes venezolanos de clases sociales bajas (de mayor presencia en el último año) ha hecho que muchos de ellos no puedan acceder a la misma por el excesivo costo que les implica pagarla, razón por la cual una buena parte de esta población está sin papeles. El costo de la visa Unasur es de 250 usD. En efecto, 35.8\% de los encuestados señaló que la principal dificultad para regularizarse es no poder pagar el costo de las visas.

Otras de las dificultades para regularizarse son: la exigencia de ciertos documentos apostillados, no contar con todos los requisitos o tener que pagar multas en caso de haber sobrepasado su tiempo en calidad de turistas (aunque los suramericanos están exentos de pago según la ley, en febrero de 2018 se emitió el Acuerdo Ministerial 904 que estipula multas por distintos tipos de incumplimientos $\left.{ }^{14}\right)$. De la encuesta realizada, $30.9 \%$ de los venezolanos señaló que no cuenta con documentos que le permitan estar regularmente en el país; $15.4 \%$ cuenta con la Tarjeta Andina que le permite estar solo 90 días; y, 28.4\% manifestó que su visa está en trámite. Datos proporcionados por la Plataforma de Coordinación para refugiados y migrantes venezolanos (Response for Venezuelans [R4V]) señalan que en Ecuador residían 385000 venezolanos hasta diciembre de 2019. Si tomamos como referencia el saldo migratorio, la cifra en el país es de 367 000, aunque este número ha disminuido en 2020 como efecto de la llegada de la Covid-19 que frenó la llegada e incrementó el retorno.

\footnotetext{
${ }^{13} \mathrm{Al}$ preguntar a los venezolanos radicados en Ecuador cuáles fueron los tres principales motivos para salir de su país respondieron: dificultades para acceder a alimentos (64.4\%), falta de trabajo o precarización $(40.2 \%)$ y falta de servicios de salud y acceso a medicamentos $(29.5 \%)$. De la encuesta realizada solo $3.3 \%$ señaló que tiene el estatuto de refugiado o es solicitante de refugio.

${ }^{14}$ Este constituye el primer acuerdo de una serie que el gobierno empieza a implementar para desmotivar la migración. Se empieza a multar con dos salarios básicos a aquellas personas que sobrepasen el tiempo que se les otorga para estar como turistas y también se establecen multas por "realizar actividades económicas que su visa no permite" (Coloma, 2020).
} 


\section{El giro en la política migratoria}

Hasta agosto de 2018 los migrantes venezolanos pudieron entrar sin mayores complicaciones, tal como establecía la Constitución, la Ley Orgánica de Movilidad Humana y el Estatuto Migratorio Ecuador-Venezuela, descritos anteriormente. Sin embargo, en dicho mes, el gobierno de Moreno empezó a modificar su política exterior y migratoria ante el incremento de llegadas de venezolanos. Se declaró situación de emergencia del sector de movilidad humana en las provincias de Carchi, El Oro y Pichincha, las de mayor tránsito migratorio, a través de la Resolución Ministerial Número 152 (MREMHU, 2018a). En dicha resolución también se habla de "mantener el estado de alerta y operativos para realizar acciones inmediatas que se requieran; así como afrontar cualquier situación negativa que se pudiera generar por el flujo migratorio inusual". Posteriormente, el Ministerio del Interior realizó un informe técnico sobre el flujo migratorio de venezolanos en donde se concluyó lo siguiente:

(...) en vista de la tendencia actual de aproximadamente 300 ingresos por día y la creciente tendencia de ingresar al país únicamente con el documento nacional de identidad, que no presenta dispositivos de seguridad que permitan comprobar la autenticidad del mismo o sin ningún documento reconocido por el país, podría impactar negativamente en el país en la capacidad nacional de prevención, control y protección de estos fenómenos, afectando los derechos de las personas en movilidad, y generando ambientes propicios para el fenómeno de los delitos asociados a la movilidad, por lo que es necesario se establezcan políticas que permitan prevenir la migración irregular y riesgosa (Ministerio del Interior Ecuador, 2018).

Inmediatamente realizado dicho informe técnico, el ministro del Interior envía un oficio a cancillería (Oficio Número MDI-DM-s-20018-0006) para solicitar "se establezcan lineamientos, directrices e instrumentos técnicos de gestión para la ejecución del control migratorio, con el fin de garantizar la protección y promoción de derechos". Esto motivó un nuevo Acuerdo Ministerial de Cancillería (Número 242) en el cual "se establece como requisito previo al ingreso a territorio ecuatoriano la presentación del pasaporte con una vigencia mínima de seis meses previa a su caducidad a los ciudadanos de la República Bolivariana de Venezuela” (Mremhu, 2018b).

Como se observa en todos estos informes técnicos, oficios y acuerdos ministeriales tanto del Ministerio del Interior como de Cancillería, hay un reforzamiento del enfoque de control y seguridad migratoria, ${ }^{15}$ amparados, como es de costumbre, en el discurso de precautelar la migración riesgosa y los derechos de los migrantes (Castro, 2018). Llama la atención que tanto el informe técnico, el oficio enviado a cancillería por el Ministerio del Interior, el Acuerdo Ministerial de Cancillería (Número 242) tienen todos fecha del 16 de agosto de 2018.

Incluso ese mismo día, el presidente de la república se reunió en el Palacio de Gobierno con un grupo de personas venezolanas para "solidarizase" con ellos, presentándose de esta manera como un gobierno humanitario, en los términos definidos en la introducción, que decide tomar acciones de prevención (declarar

\footnotetext{
${ }^{15}$ Que también se puede ver en el incremento de deportaciones, inadmisiones y "salidas voluntarias" en lo que va del gobierno de Moreno.
} 
estado de emergencia). Los nombra "hermanos migrantes", les da la bienvenida, los reconoce como víctimas del gobierno de Maduro y señala que "jamás desconocerá sus derechos humanos". Con esto se observa con nitidez cómo se construyen los nexos entre humanitarismo de prevención y seguridad.

En un despliegue gubernamental nunca visto, que incluyó a varias carteras de Estado y al propio presidente Moreno, en un solo día, cambió el enfoque de las políticas migratorias que se venían construyendo. Esto ha sido catalogado por algunos juristas, expertos en la materia, organizaciones no gubernamentales y defensores de derechos como una clara violación a la Constitución, a la Ley de Movilidad Humana, así como a acuerdos bilaterales y multilaterales firmados en el seno de la Comunidad Andina (CAN), Mercado Común del Sur (Mercosur) y Unasur referentes al derecho a migrar, a la ciudadanía suramericana y a la movilidad intrarregional con la presentación del documento nacional de identidad.

Por lo expuesto, estas medidas provocaron reacciones de diferentes actores de la sociedad que trabajan con inmigrantes, quienes se pronunciaron en contra del gobierno e interpusieron medidas cautelares. Si bien se logró eliminar el requisito de entrar solo con pasaporte (documento muy complicado de conseguir en Venezuela), la Cancillería Ecuatoriana emitió un nuevo Acuerdo Ministerial (Número 244) en el que se señala que los ciudadanos venezolanos podrán ingresan a Ecuador con cédula de identidad siempre y cuando cumplan con uno de los dos tipos de validación:

(...) con la presentación de un certificado de validez de la cédula de identidad, emitido por un organismo regional o internacional reconocido, o con la presentación de un certificado de validez de la cédula de identidad emitido por las entidades autorizadas al efecto por el gobierno de la República Bolivariana de Venezuela debidamente apostillado (MREMHU, 2018c).

El resultado de tales políticas no fue el descenso de los ingresos de venezolanos, que era lo que buscaba el gobierno tal como se lee en los informes técnicos. ${ }^{16}$ Vale señalar que, según un estudio realizado por la Organización Internacional para las Migraciones (оIM, 2018), en los mismos meses que se daban estos cambios en las políticas migratorias (agosto y septiembre), 69\% de los migrantes venezolanos que ingresaron al Ecuador lo hacían con pasaporte y $30 \%$ ingresaron con cédula de identidad. Dicho estudio también revela que $9 \%$ ingresó a territorio ecuatoriano por un cruce informal, hecho que puede haber sido un efecto de las medidas tomadas. Es decir, las medidas no disminuyeron las llegadas como se esperaba, pero provocaron que un porcentaje ingresara por pasos fronterizos clandestinos:

No es secreto para nadie que los venezolanos están pasando por las trochas, se paga por pasar 30 dólares, fui a la frontera a inicios de diciembre y pude ver galpones donde hay venezolanos esperando para que los pasen por las trochas. En los galpones vi que estaban como 200 personas sentadas esperando que las pasen, en la Panamericana se ve personas que están caminando (presidente de la Asociación Migrante Universal, 2 de diciembre de 2019, citado en Coloma, 2020).

${ }^{16}$ Dos meses después de aplicada la norma, el ingreso de venezolanos llegó hasta 806616. 
A este contexto se suma el evento de feminicidio ocurrido a principios de 2019 en la ciudad de Ibarra que dio paso a ver a los migrantes venezolanos como una metaamenaza al orden social, económico y a la seguridad nacional, por ende, se pasa de un humanismo de prevención hacia uno de expiación. Moreno cambió su discurso piadoso y compasivo de meses anteriores e hizo visible su "xenofobia presidencial" (Borja, 2019). En su cuenta de Twitter manifestó:

Ecuador es y será un país de Paz. No permitiré que ningún antisocial nos arrebate... He dispuesto la conformación inmediata de brigadas para controlar la situación legal de los inmigrantes venezolanos en las calles, en los lugares de trabajo y en la frontera. Analizamos la posibilidad de crear un permiso especial de ingreso al país. Les hemos abierto las puertas pero no sacrificaremos la integridad de nadie. Es deber de la Policía actuar duramente contra la delincuencia y la policía tienen mi respaldo... (Moreno, 20 de enero de 2019).

Un día después de este anuncio el Ministerio del Interior y la Cancillería Ecuatoriana sacaron un nuevo Acuerdo Interministerial (Número 001) en cuyos considerandos se recuerda la facultad del Estado de registrar ingresos y salidas, inadmitir a personas extranjeras "que sean consideradas una amenaza o riesgo para la seguridad interna", entre otros, además acuerdan:

Requerir a los ciudadanos venezolanos que deseen ingresar a territorio del Ecuador, además de los documentos establecidos en el Acuerdo Ministerial No 244, la presentación del Certificado de Antecedentes Penales del país de origen, del país de residencia durante los últimos cinco años, debidamente apostillado o legalizado (Acuerdo Interministerial No 001, 21 de enero de 2019).

De esta disposición quedaron exentos los menores de edad, personas que tengan vínculos familiares con ecuatorianos hasta segundo grado, los que tengan visa vigente y aquellos que utilicen Ecuador como ruta de tránsito pero que acrediten poseer una visa del país de destino (Acuerdo No 002). Esta nueva medida, de solicitar pasado judicial apostillado, no solo viola una vez más el marco legal, sino que en la práctica convierte al Ecuador en un estado tapón de dicha migración que viene por Colombia y que se dirige a algún país de la región. ${ }^{17}$ Este acuerdo vino acompañado de mayores controles, incluida la militarización de la frontera norte y, en contraparte, protestas de los migrantes venezolanos al no poder seguir su camino. Una vez más varias instituciones de defensa de derechos de los migrantes interpusieron una acción pública de inconstitucionalidad ante la Corte Constitucional para dejar sin efecto tales medidas, quienes lograron su objetivo de suspender provisionalmente dichas políticas en marzo de 2019.

Si bien se pudieron frenar temporalmente a nivel jurídico las medidas puestas por el gobierno, a nivel social se dio rienda suelta a odios, brotes de xenofobia e intolerancia en contra de los migrantes, lo que convirtió al venezolano en el chivo expiatorio de varios problemas que enfrenta el país como la delincuencia, desempleo, criminalidad,

\footnotetext{
${ }^{17}$ De los venezolanos que están en Ecuador, $25 \%$ señaló en la encuesta que su destino final era otro país, principalmente Chile y Perú.
} 
entre otros. Varias encuestas de percepción ciudadana colocan a la migración entre los principales problemas que enfrenta el Ecuador. ${ }^{18}$

Este asunto llegó a su nivel máximo cuando a finales de enero ocurrió un feminicidio en la ciudad de Ibarra, el cual fue grabado y transmitido en vivo por redes sociales. Durante aproximadamente 45 minutos una persona tuvo de rehén a su pareja amenazada con un cuchillo mientras la policía y la ciudadanía observaban impávidos. Después de ocurrido este crimen, se supo que el marido de la víctima era venezolano y tras las declaraciones del presidente de la República señaladas anteriormente, la población de Ibarra literalmente fue a la "caza" de ellos en hostales y hoteles, quemaron sus pocas pertenencias, insultaron, golpearon y apedrearon a todo venezolano que estaba por la calle sin importar sexo ni edad.

Los resultados de esta barbarie, denominada por los ibarreños como "limpieza social", fue la salida masiva de venezolanos de aquella ciudad, que se escondieran y no salieran a las calles en otros lugares del país por temor a ser agredidos; el endurecimiento de políticas securitistas para impedir su llegada mediante la resolución de nuevos acuerdos y reforzamientos de controles en la frontera; una nueva escalada de tensiones diplomáticas entre Ecuador y Venezuela y el retorno de miles de venezolanos hacia su país. Hay que señalar que el hostigamiento, la xenofobia y la explotación son la segunda causa por las cuales los venezolanos deciden regresar a Venezuela. De la encuesta realizada, $48.5 \%$ de los venezolanos señaló que se ha sentido discriminado. ${ }^{19}$

El anuncio de la entrada en vigor de la visa a venezolanos para ingresar a Perú (a partir del 15 de junio de 2019) produjo un nuevo incremento de migrantes venezolanos en tránsito. A diferencia de lo ocurrido entre agosto y septiembre de 2018, cuando el gobierno implementó un corredor humanitario para transitar por todo el territorio ecuatoriano, esta vez el apoyo a los miles de migrantes que entraban al país desde Colombia lo dieron el gobierno de la provincia de Pichincha, algunas ONG y organismos internacionales. ${ }^{20}$

La medida impuesta por Perú tuvo su efecto dominó en Chile y Ecuador, quienes realizaron acciones similares. Sin embargo, para el caso ecuatoriano hay dos elementos centrales de su política exterior y diplomacia migratoria que es necesario analizar para entender las últimas medidas tomadas por el gobierno. A nivel de su política exterior, en marzo del año 2019 el Ministro de Relaciones Exteriores comunicó formalmente a la presidencia pro tempore de Unasur la decisión del gobierno ecuatoriano de "iniciar los procedimientos internos para la denuncia del tratado". Dichos procesos terminaron con la aprobación por el pleno de la Asamblea Nacional de la denuncia del tratado a finales del mismo año.

\footnotetext{
${ }^{18}$ En la encuesta de Celag (noviembre de 2018) y Clima Social (noviembre de 2019) la migración aparece como uno de los principales problemas después del empleo y la inseguridad.

${ }^{19}$ Con el Plan Vuelta a la Patria implementado por el gobierno de Venezuela se han inscrito para retornar 100426 personas y han regresado 17522 venezolanos (hasta febrero de 2020). Desde Ecuador regresaron 3242 personas en 36 puentes aéreos Vale señalar que los retornos aumentaron a partir de marzo de 2020 con la llegada de la Covid-19.

${ }^{20}$ Funcionarios de varias carteras de Estado señalaron que dadas las políticas de austeridad implementadas por el gobierno central en el área social no les era factible colaborar. Incluso las precarias condiciones en las que se encuentran los Centros Binacionales de Atención Fronterizos (Cebaf), sin acceso a agua, ni aire acondicionado se debe a estos recortes en el área social.
} 
Si bien el principal motivo de la salida de este espacio regional era alejarse de la política internacional realizada por el anterior gobierno de Correa, los otros motivos eran múltiples y buscaban dar una señal a la región de su giro al incorporarse al Grupo de Lima (véase MPPRE, 2020), pedir formalmente su inclusión como Estado asociado en la Alianza del Pacífico y ser miembro fundador del Foro para el Progreso de Suramérica (Prosur). ${ }^{21}$ Entonces, la salida de Unasur implicaba cambiar algunas de sus normativas internas, entre ellas la Ley de Movilidad Humana.

Es por esto por lo que el gobierno envía a finales de julio de 2019 un Proyecto de Ley Orgánica Reformatoria a la Ley de Movilidad Humana a la Asamblea donde se elimina cualquier mención a Unasur, y se deja abierta la posibilidad de poner visas de entrada: "El Estado ecuatoriano podrá establecer mecanismos temporales de autorización de ingreso para ciudadanos suramericanos ante casos de necesidad debidamente fundamentados" (artículo 34, Proyecto de Ley Orgánica Reformatoria). De igual manera, el proyecto de ley apunta a optimizar los procesos de deportación de ciudadanos extranjeros que infrinjan la ley. En términos generales, en dicho proyecto sobresale el cambio de la política migratoria al establecer criterios más fuertes en torno a la seguridad, la soberanía y el control.

Vale resaltar que, pese a enviar esta propuesta de Ley a la Asamblea, hay un dictamen favorable de la Corte Constitucional en relación con la denuncia del tratado constitutivo de la Unasur, donde se señala que la salida del Ecuador de este espacio regional podría tener un carácter regresivo, en caso de que disminuya o menoscabe el ejercicio de los derechos migratorios de las personas pertenecientes a Unasur y que podría tener efectos inconstitucionales. El dictamen señala:

Establecer que los derechos de las personas adquiridas, en virtud de lo establecido en los artículos 83 al 89 [referente a la ciudadanía suramericana] de la Ley Orgánica de Movilidad Humana, deberán ser respetados y garantizados, mediante las medidas administrativas, legislativas yjudiciales que correspondan (Corte Constitucional del Ecuador, 2019).

El gobierno ha hecho caso omiso a tal dictamen, no solo envió un proyecto de ley reformatorio que vulnera derechos de los migrantes, sino que emitió un nuevo decreto (No 826) para imponer una visa de ingreso a venezolanos:

Requerir a todo ciudadano venezolano, para el ingreso a la República del Ecuador, la presentación de la visa de residencia temporal de excepción por razones humanitarias, la visa consular de turismo o cualquier otra visa prevista en la Ley Orgánica de Movilidad humana (Artículo 5, Decreto No 826).

Dicho decreto provocó nuevamente un incremento de flujos en la frontera norte de migrantes venezolanos que querían ingresar al país antes de que este entrara en vigor (26 de agosto de 2019). Según datos de la cancillería, hasta antes de la entrada en vigor del decreto ingresaron en promedio 7,704 personas por día. Como se observa en la Figura 5, antes del anuncio del mencionado decreto, las entradas de venezolanos empezaban a disminuir (julio) pero volvieron a dispararse en agosto, para llegar a su pico más alto de todo el año, y luego descender abruptamente a partir de septiembre. Se pasó en un mes de 91,000 a 2,500 entradas, aproximadamente. El gobierno

\footnotetext{
${ }^{21}$ Espacio creado en el 2019 en remplazo de Unasur y conformado inicialmente por Colombia, Chile, Ecuador, Perú y Paraguay.
} 
había cumplido su objetivo de controlar y restringir el paso regular por territorio ecuatoriano, lo que provocó que miles de venezolanos se quedaran varados en la frontera entre Colombia y Ecuador o que usen pasos clandestinos (mejor conocidos como "trochas").

Figura 5. Entradas de venezolanos, enero-diciembre de 2019

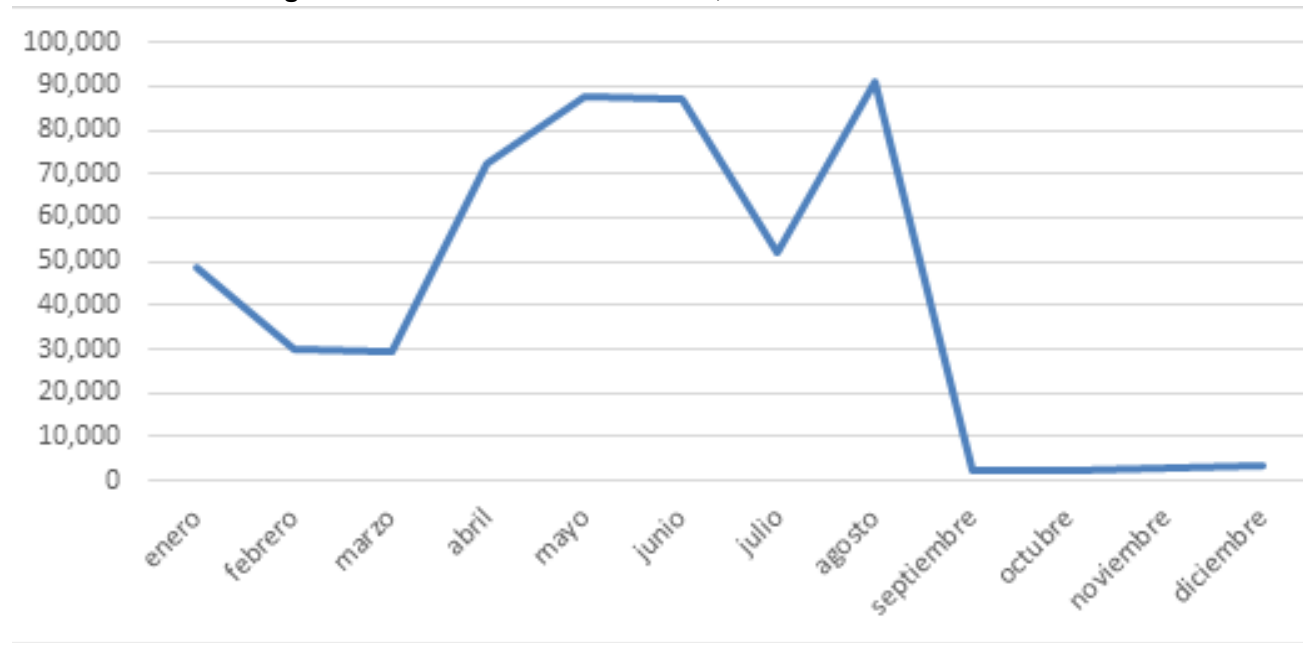

Fuente: Elaboración propia con base en información del Ministerio de Gobierno, Ecuador.

Se resalta que las visas de ingreso se entregan solamente en las oficinas consulares de Caracas, Bogotá y Lima, tal como quedó estipulado en el Acuerdo Ministerial 103 (MREMHU, 2019a).

El otro elemento a nivel de la diplomacia migratoria liderado por Ecuador es el surgimiento del Proceso de Quito que se inició en septiembre de 2018, en el cual sobresalen dos temas en las declaraciones. Primero, se enfatiza en la necesidad de mayor apoyo internacional hacia los países de tránsito y destino de la migración venezolana. Por eso en las declaraciones finales se hace hincapié en que "se incremente el apoyo técnico y financiero internacional", "la necesidad de una mayor cooperación financiera y técnica" y "urgir que la cooperación y recursos se incrementen".

Como se observa en dichas declaraciones y en las acciones diplomáticas implementadas por cancillería, se utiliza el tema migratorio, específicamente la "ayuda humanitaria” que el gobierno está brindando, como estrategia de su política exterior para conseguir fondos de cooperación internacional ${ }^{22}$ y a su vez para presionar al gobierno de Venezuela. Este espacio, junto al Grupo de Lima, son los que colocaron los términos de "éxodo migratorio" y "crisis humanitaria en Venezuela".

En este sentido, como segundo tema central, se hace un llamado a "la apertura de mecanismos de asistencia humanitaria", a desarrollar dispositivos de "regularización, armonización y coordinación regional”. Es por esto por lo que en los considerandos

\footnotetext{
${ }^{22}$ Ecuador en su "Informe sobre la emergencia migratoria venezolana y su impacto en el Ecuador" señala que en 2018 empleó 76823009 millones de dólares del presupuesto ordinario para hacer frente al flujo de venezolanos (MREMHU, 2019b) y recibió aproximadamente 20000000 uSD de cooperación internacional. Según cifras oficiales del gobierno nacional, se requieren 550000000 uSD para dar una respuesta integral a las personas venezolanas (MREMHU, 2018d).
} 
del Decreto 826 se cita reiteradamente al Proceso de Quito y se decide otorgar una "amnistía migratoria para todas las ciudadanas y ciudadanos venezolanos que no hayan violado las leyes del Ecuador" (Artículo 1. Decreto No 8.26). Se decide crear una nueva visa llamada de "residencia temporal de excepción por razones humanitarias" (Verhu), la cual se empezó a otorgar desde finales de octubre de 2019. En dicho decreto se establece que serán beneficiados los venezolanos que:

hayan ingresado regularmente a través de los puntos de control migratorio al territorio del Ecuador hasta la fecha de entrada en vigencia del Decreto Ejecutivo, o que habiendo ingresado regularmente al Ecuador a través de los puntos de control migratorio, se encuentren en condición migratoria irregular por haber excedido el tiempo de permanencia otorgado a la fecha de entrada en vigencia del presente Decreto Ejecutivo (Decreto No 826).

Esta imposición de visa - a la cual el canciller de Ecuador considera como un gesto de "hermandad real" y "extremadamente solidaria" - solo aplica para aquellos que entraron hasta el 25 de julio de 2019 y tiene como prerrequisito obligatorio la inscripción en línea a través del portal virtual del Ministerio de Gobierno.

Llama la atención que el proceso de otorgamiento de dicha "visa humanitaria" la lleva el Ministerio de Gobierno, a través de la Subsecretaría de Migración, y no el Ministerio de Relaciones Exteriores y Movilidad Humana que, según la ley, es el encargado de otorgar todas las visas.

El interesado en obtener la visa tiene que llenar un formulario en línea y responder 44 preguntas a partir de las cuales el Estado obtiene información detallada sobre cada solicitante. Varias preguntas tienen que ver, por un lado, con el tema económicolaboral: ¿tiene ocupación?, ¿tiene trabajo?, ¿tiene salario menor al básico (394 USD)?, ¿tuvo trabajo fijo durante el último mes?, ¿tiene contrato? En otro ámbito, hay preguntas vinculadas a obtener información sobre salud: ¿han contraído alguna enfermedad infectocontagiosa?, ¿padecen de alguna enfermedad crónica?, ¿acuden o han acudido a un centro de salud público o privado en Ecuador? En esta sección se incluye una pregunta sobre el pasado judicial: ¿han cometido infracción o delito? Esta información se pide tanto al solicitante como a su familia.

Una vezque se termina de llenar el formulario se genera un código de autenticación y se solicita un turno que es enviado al correo electrónico del solicitante. El día de la cita, a la cual se debe acudir a las oficinas del Servicio de Apoyo Migratorio del Ministerio de Gobierno portando algún documento de identificación, el proceso continúa con la verificación de toda la información ingresada en digital y termina con el llamado empadronamiento biométrico, es decir, la toma de fotos y huellas digitales. Las personas calificadas, previo al otorgamiento de la visa, tienen que pagar el valor de 50 usD. Dicha amnistía que autoriza una residencia temporal culminaba el 31 de marzo de 2020, sin embargo, por motivos de la pandemia, se extendió hasta el 13 de agosto. Hasta finalizar el proceso se aprobaron 38243 visas humanitarias, aproximadamente $86.25 \%$ de ellas se otorgó en Ecuador y $13.75 \%$ en el exterior. ${ }^{23} \mathrm{El}$ dato de visas humanitarias concedidas, en relación con el número de personas que se registraron en línea ( 235000 , aproximadamente) confirma que son muy pocas las visas entregadas, apenas $16 \%$.

${ }^{23}$ De las 5257 visas que se otorgaron en los consulados, $87.5 \%$ se entregaron en Caracas, $11.1 \%$ en Bogotá y $1.4 \%$ en Lima (MREMHU, 2020). 
Esto se debe, según algunos informantes, a que dicha amnistía no contempla mecanismo de regularización alguno para las personas que hicieron su ingreso en migración presentando otro documento distinto al pasaporte. Dichos venezolanos no solo quedan fuera de la amnistía, sino que también son susceptibles a la deportación, tal como dispone el Decreto y, como algunos informantes comentaron, ya empezó a ocurrir bajo la figura de "salida voluntaria".

Son evidentes las diferencias entre la visa Unasur y la visa humanitaria. Mientras la primera está pensada como un mecanismo permanente para todos los ciudadanos suramericanos bajo un enfoque de derechos otorgada por el ministerio de Relaciones Exteriores y Movilidad Humana, la segunda, emitida por el Ministerio de Gobierno, es exclusiva para ciudadanos venezolanos, es de carácter transitorio y concebida bajo el enfoque no solo de seguridad y control sino de salud pública. ${ }^{24}$

En síntesis, desde que el presidente Moreno asumió el poder hemos visto un giro, no solo en la política sino en el discurso de su equipo de gobierno en torno a la migración venezolana, desde la solidaridad con "los hermanos migrantes que huyen de la dictadura de Maduro", pasando por "hay que resguardar las fronteras para que no llegue gente mala", hasta "vienen a desestabilizar el país". En efecto, en el marco de las manifestaciones del mes de octubre de 2019, las cuales fueron una respuesta popular a las medidas neoliberales y autoritarias (Ramírez, 2020), el gobierno acusó a los venezolanos, al presidente Maduro y al expresidente Correa de estar atrás de un intento de golpe de Estado:

"Más que sospechas o temores es realidad. Hay decenas de ciudadanos de otra nacionalidad (...) Del país del señor de los bigotes ... Ciudadano extranjero que se presente para generar el caos, la violencia y la delincuencia en Ecuador, que es un territorio de paz. Extranjero que no cumpla con las leyes del país y ofenda a los ecuatorianos, no podrá seguir en el Ecuador" (Otto Sonnenholzner, vicepresidente de la República del Ecuador, hasta julio de 2020).

"Los actos de violencia mostraron una gran coordinación y preparación táctica (...) hay una serie de pruebas muy preocupantes que vinculan a Venezuela con los disturbios violentos (...) de las 1330 personas detenidas durante los doce días de protestas, 41 de ellas son de nacionalidad venezolana” (José Valencia, ministro de Relaciones Exteriores y Movilidad Humana, hasta agosto de 2020).

Pese a que todos los venezolanos detenidos fueron declarados inocentes, como se observa en las declaraciones de las principales autoridades del gobierno, utilizaron la presencia de migrantes de esta nacionalidad en Ecuador para culparles de estar atrás de los actos violentos, de la desestabilización y del intento de golpe de Estado. Estos argumentos fueron llevados al ámbito internacional y denunciados en la Organización de Estados Americanos (oeA).

Estos hechos nos recuerdan lo señalado por Adamson y Tsourapas (2019), que los estados pueden usar la diplomacia migratoria por motivos de seguridad nacional cuando consideran que los flujos migratorios son conductos para el terrorismo, el

\footnotetext{
${ }^{24}$ Vale resaltar que en 2020 (entre enero y septiembre) se entregaron apenas 5848 visas Unasur. Pese a que aún están vigentes el gobierno ha dejado de otorgarlas.
} 
crimen organizado o la desestabilización interna. Además, los estados también pueden activar la diplomacia migratoria para justificar mayores controles fronterizos, imponer nuevas restricciones de ingreso o con el fin de expulsar o deportar. Esto ha realizado el gobierno de Ecuador y con estas prácticas se han violentado los derechos humanos.

\section{Conclusiones}

Sin lugar a duda la migración venezolana cambió el "paisaje migratorio" de la región latinoamericana y en particular de los países de la costa del Pacífico sur, quienes fueron los principales receptores. Uno de ellos Ecuador, país tradicionalmente de emigración, actualmente es más de tránsito y destino.

La historia de las migraciones nos enseña la importancia del análisis longitudinal para ver los cambios, continuidades y patrones de los flujos migratorios. Venezuela dejó de ser el principal país de atracción de migrantes en Suramérica (junto con Argentina) para convertirse en el principal expulsor de la región.

Aunque ya se ha dicho mucho sobre las causas de la migración venezolana (Blouin, 2019; Gandini, et al., 2019) los efectos en los países receptores y sobre todo las políticas implementadas, así como la diplomacia migratoria en torno a este flujo, todavía es tarea pendiente. Este texto ha querido contribuir en el entendimiento de las políticas y diplomacia migratoria implementada en Ecuador a través del análisis de las medidas tomadas por el gobierno de Moreno.

$\mathrm{Al}$ revisar el actual accionar gubernamental, está claro el rumbo que este ha tomado. Si bien uno observa en los principales planes de política pública en esta materia un enfoque de derechos, ${ }^{25}$ cuando dejamos de "creer a pie juntillas" en los planes elaborados "por arriba" y nos sumergimos al análisis de los decretos, resoluciones, proyecto de ley migratoria, registro migratorio para obtener visa humanitaria y las declaraciones de las autoridades aquí analizados se ve con nitidez su nueva orientación, la cual pasó de ver a los migrantes venezolanos como víctimas para considerarlos una amenaza. Esto implicó una restricción de los flujos, el reforzamiento y mayores controles en las fronteras y retorno del enfoque de seguridad nacional, el cual —con la llegada de la pandemia - se agudizó aún más.

Ecuador, en el gobierno de Correa, aprobó un marco constitucional y jurídico en materia migratroria que utilizó como instrumento para su política exterior al proponer libre movilidad, ciudadanía universal y derecho a migrar, entre otros tópicos que puso sobre la mesa de diálogo a nivel internacional.

Desde una preocupación por la integración regional y con una política pro derechos, concretó varios acuerdos interestatales para dar facilidades a la movilidad intrarregional, uno de ellos con el gobierno de Venezuela. A esto hay que sumar la inclusión de la categoría de ciudadanía suramericana en la Ley de Movilidad Humana que permitió que los venezolanos ingresen libremente y puedan residir en el país presentando requisitos sencillos.

\footnotetext{
${ }^{25}$ Véase Plan Nacional de Movilidad Humana (2018), Plan Integral para el Mejoramiento de los Servicios Ciudadanos (2018), y el Plan integral para la atención y protección de derechos en el contexto del incremento del flujo migratorio venezolano en Ecuador (2018).
} 
Lamentablemente, el actual gobierno del presidente Moreno empezó a imponer restricciones para su llegada, las cuales concluyeron en la imposición de una visa denominada "visa de residencia temporal de excepción por razones humanitarias".

La imposición de esta visa de ingreso, sumada a la propuesta de nueva Ley de Movilidad Humana, la salida de Unasur, el retiro del asilo diplomático a Julian Assange, la expulsión del embajador de Venezuela en Ecuador (por motivos vinculados con la migración), culpar a algunos migrantes venezolanos, a Maduro y a los coidearios del ex presidente Correa de estar atrás del estallido social de octubre de 2019, sumarse al Grupo de Lima, a Prosur y, por supuesto, reconocer a Juan Guaidó como presidente de Venezuela, configuran hitos centrales que hablan del alineamiento de Moreno a la agenda de Washington y del giro en su política exterior.

Para cumplir tal empresa, el actual gobierno ha realizado una diplomacia migratoria como una estrategia para uno de los objetivos centrales de su política internacional: atacar al gobierno de Nicolás Maduro y utilizar el flujo de migrantes y refugiados como la prueba más palpable del fallido "socialismo del siglo xxi" en Venezuela. A esto hay que sumar que el gobierno de Ecuador fue el que impulsó el llamado Proceso de Quito (espacio que al surgir estancó por dos años a la Conferencia Suramericana de Migraciones) que fue utilizado como plataforma multilateral para la búsqueda de fondos de cooperación internacional que era otro de los objetivos de su diplomacia migratoria, así como para justificar las nuevas medidas implementadas, las cuales adquirieron un tinte securitista.

Finalmente, no se debe dejar pasar por alto el hecho de que en el marco de la gestión de los flujos migratorios de venezolanos hay un trasfondo geopolítico complejo que está determinando, de manera significativa, las relaciones internacionales y diplomáticas en América Latina.

\section{Referencias}

Adamson, F. \& Tsourapas, G. (2019). Migration diplomacy in world politics. International Studies Perspectives, 20(2), 113-128. https://doi.org/10.1093/isp/eky015

Banda, C. \& Lesser, M. (1987). Los que se van: la migración manabita a Venezuela. En L. Barriga (Ed.), Sociedad y derechos humanos (pp. 193-242). Urshslac-Unesco.

Blouin, C. (Coord.). (2019). Después de la llegada. Realidades de la migración venezolana. Themis-PUCP.

Borja, M. (2019). Xenofobia presidencial. GK. https://gk.city/2019/01/21/lxenofobia-comunicado-lenin-moreno-venezolanos-ibarra/

Castro, Y. (2018). Migración y fronteras en el fetichismo de la ley. Revista Urvio, (23), 29-43. https://doi.org/10.17141/urvio.23.2018.3521

Ceja, I. \& Ramírez, J. (en prensa). Migración haitiana en Ecuador: entre los vaivenes del discurso humanitario, las políticas de exclusión y los proyectos migratorios. En C. Audebert \& A. Joseph (Coords.), Migración haitiana por Suramérica. Clacso.

Clavijo, J., Pereira, A. \& Basualdo, L. (2019). Humanitarismo y control migratorio en Argentina: refugio, tratamiento médico y migración laboral. Apuntes, 46(84), 127-157. http://dx.doi.org/10.21678/apuntes.84.1016 
Coloma, S. (2020). Informe final del estudio cualitativo de la situación de las personas inmigrantes en la Provincia de Pichincha. GadPP.

Corte Constitucional del Ecuador. (2019, 18 de julio). Dictamen Denuncia del Tratado Constitutivo de la Unión de Naciones Suramericanas (Unasur). Quito.

Deleuze, G. (1991). Foucault. Paidós.

Domenech, E. (2017). Las políticas de migración en Sudamérica: elementos para el análisis crítico del control migratorio y fronterizo. Terceiro Milênio. Revista Crítica de Sociologia e Política, 8(1), 19-48. https://ri.conicet.gov.ar/handle/11336/58156

Fassin, D. (2016). La razón humanitaria. Una historia moral del tiempo presente. Siglo XXI.

Fassin, D. (2018). Por una repolitización del mundo. Las vidas descartables como desafío del siglo XXI. Siglo XXI.

Gandini, L., Lozano, F. \& Prieto, V. (2019). Crisis y migración de población venezolana. Entre la desprotección y la seguridad jurídica en Latinoamérica. UNAM.

Gissi, N., Ramírez, J., Ospina, M., Cardoso, P. \& Polo, S. (2020). Respuestas de los países del pacífico suramericano ante la migración venezolana: estudio comparado de políticas migratorias en Colombia, Ecuador y Perú. Diálogo Andino, (63).

Herrera Ríos, W. (2016). Rediseñando la presencia estatal extraterritorial: el manejo político e institucional de la emigración bajo la Revolución Ciudadana del Ecuador. En M. Le Quang, (Ed.), La Revolución Ciudadana en escala de grises. Avances, continuidades y dilemas (pp. 105-131). IAEN.

Ménard, M. (2017). Ecuador como nodo articulador de la migración senegalesa en América del Sur. Migracion y Desarrollo, 15(29), 31-50. https://doi.org/10.35533/ myd.1529.amm

Ministerio de Relaciones Exteriores y Movilidad Humana (Mremhu). (2008). Boletín de Prensa No. 398, Quito.

Ministerio de Relaciones Exteriores y Movilidad Humana (mremhu). (2018a, 9 de agosto). Acuerdo Ministerial No 152. Viceministerio de Movilidad Humana, Quito.

Ministerio de Relaciones Exteriores y Movilidad Humana (Mremhu). (2018b, 16 de agosto). Acuerdo Ministerial No 242. Viceministerio de Movilidad Humana, Quito.

Ministerio de Relaciones Exteriores y Movilidad Humana (mRemhu). (2018c, 26 de agosto). Acuerdo Ministerial No 244. Viceministerio de Movilidad Humana, Quito.

Ministerio de Relaciones Exteriores y Movilidad Humana (Mremhu). (2018d). Marco de Cooperación Internacional para la respuesta nacional a las personas venezolanas en situación de movilidad humana en Ecuador, Quito.

Ministerio de Relaciones Exteriores y Movilidad Humana (мremhu). (2019a, 26 de julio). Acuerdo Ministerial No 103. Visa de Excepción por razones humanitarias a ciudadanos venezolanos, Quito.

Ministerio de Relaciones Exteriores y Movilidad Humana (mRemhu). (2019b). Informe sobre la emergencia migratoria venezolana y su impacto en el Ecuador (Oficio MREMH-2019-0580-OF). Quito. 
Ministerio de Relaciones Exteriores y Movilidad Humana (мremhu). (2020, 14 de agosto). Regularización de ciudadanos venezolanos en Ecuador. Quito.

Ministerio del Interior Ecuador. (2018, 16 de agosto). Informe técnico de situación flujos migratorios inusuales de ciudadanos venezolanos. Quito.

Ministerio del Poder Popular para Relaciones Exteriores (MPPRE). (2020). Plan Vuelve a la Patria. Gobierno Bolivariano de Venezuela. http://mppre.gob.ve/wp-content/uploads/2019/02/2019-02-04_Bolet\%C3\%ADn_Vuelta_a_la_Patria_ESP. pdf

Moreno, G. (2019). Migración indocumentada cubana por Centroamérica: El papel de Nicaragua en la crisis migratoria de 2015. Estudios Fronterizos, 20, https://doi. org $/ 10.21670 /$ ref. 1917038

Organización Internacional para las Migraciones (OIM). (2018, agosto-septiembre). Monitoreo de flujo de población venezolana por Ecuador. Ronda 2. Displacement Tracking Matrix (DTM). onU. http://oim.org.ec/pdf/DTM\%20Ronda\%202.pdf

Penchaszadeh, A. \& García, E. (2018). Política migratoria y seguridad en Argentina hoy: ¿el paradigma de derechos humanos en jaque? Urvio, (23), 91-109. https:// doi.org/10.17141/urvio.23.2018.3554

Pereira, A. (2019). El nexo entre migración, seguridad y derechos humanos en la política migratoria Argentina (1990-2015). Desafíos, 31(1), 273-309. https://doi. org/10.12804/revistas.urosario.edu.co/desafios/a.6031

Pugh, J., Jiménez, L. \& Latuff, B. (2020, 9 de enero). Welcome wears thin for Colombians in Ecuador as Venezuelans become more visible. Migration Policy Institute. https://www.migrationpolicy.org/article/welcome-wears-thin-for-colombians-ecuador

Ramírez, F. (2020). Octubre y el derecho a la resistencia. Revuelta popular y neoliberalismo autoritario en Ecuador. Clacso. http://biblioteca.clacso.edu.ar/clacso/ se/20200519040510/Ecuador.pdf

Ramírez, J. (2013). La política migratoria en Ecuador. IAEN. https://www.aacademica. org/jacques.ramirez/2

Ramírez, J. (2014). Del aperturismo segmentado al enfoque de derechos: una mirada histórica de la política migratoria en el Estado Ecuatoriano. En P. Galeana (Coord.), Historia comparada de las migraciones en las Américas (pp. 139-160). UNAM. http://ru.juridicas.unam.mx/xmlui/handle/123456789/12716

Ramírez, J. (2016). Hacia el Sur. La construcción de la ciudadanía suramericana y la movilidad intrarregional. Celag. https://www.celag.org/wp-content/uploads/2016/10/hacia-el-Sur_Vfinal-16-03-2.pdf

Ramírez, J. (2017). Lo crudo, lo cocido y lo quemado: Etnografía de la ley de movilidad humana de Ecuador. En J. Ramírez (Comp.), Migración, Estado y Políticas (pp. 93127). Vicepresidencia de Bolivia/Celag. https://www.aacademica.org/jacques. ramirez/10

Ramírez, J., Linárez, Y. \& Useche, E. (2019). (Geo)Políticas migratorias, inserción laboral y xenofobia: migrantes venezolanos en Ecuador. En C. Blouin (Coord.), Despúes de la llegada. Realidades de la migración venezolana (pp. 103-127). Themis-PUCP.

Ramírez, R. (2019). La vida y el tiempo. Apuntes para una teoría ucrónica de la vida buena a partir de la historia reciente del Ecuador (tesis doctoral inédita). Universidad de Coimbra. 
Ticktin, M. (2011). Casualties of care. Immigration and the politics of humanitarianism in France. University of California Press.

Ticktin, M. (2015). Los problemas de las fronteras humanitarias. Revista de Dialectología y Tradiciones Populares, 70(2), 291-297. https://doi.org/10.3989/ rdtp.2015.02.001.03

Tsourapas, G. (2017). Migration diplomacy in the Global South: cooperation, coercion and issue linkage in Gaddafi's Libya. Third World Quarterly, 38(10), 23672387. https://doi.org/10.1080/01436597.2017.1350102

Uebel, R. \& Ranincheski, S. (2017). Pontes ou muros? As diferentes ações dos governos de Lula da Silva, Dilma Rousseff e Michel Temer em relação às migrações internacionais para o território brasileiro. Oikos, 16(2), 79-100. https:// www.researchgate.net/publication/321808513_Pontes_ou_muros_As_diferentes_acoes_dos_governos_de_Lula_da_Silva_Dilma_Rousseff_e_Michel_Temer_ em_relacao_as_migracoes_internacionais_para_o_territorio_brasileiro

Villareal, M. (2019, 7 de noviembre). La cooperación regional ante la migración venezolana: El grupo de Lima y el Proceso de Quito en perspectiva comparada [Ponencia]. I Congreso Internacional de Movilidad Humana colombo-venezolana, Cúcuta.

Jacques Ramírez

Ecuatoriano. Doctor en antropología social por la Universidad Iberoamericana, Ciudad de México. Profesor en el Programa de Antropología de lo Contemporáneo, Universidad de Cuenca, Ecuador. Investigador de Celag. Línea de investigación: migración y políticas. Publicaciones recientes: Ramírez Gallegos, J. \& Umpierrez de Reguero, S. (2019). Estado, (e)migración y voto: análisis longitudinal de la experiencia ecuatoriana (2006-2019). Odisea. Revista de Estudios migratorios, (6), 31-64; Ramírez, J., Ceja, I. \& Alfaro, Y. (2019). La Conferencia Sudamericana de Migraciones y el Proceso Puebla: ¿entre la seguridad y los derechos? Periplos. Revista de Investigación sobre Migraciones, 3(1). 